\title{
A onipresença da arte religiosa na educação cristã metodista no Brasil entre 1890 e 1930: a abrangência do fenômeno e seu significado ambíguo
}

\author{
The omnipresence of religious art in Methodist \\ Christian education in Brazil between 1890 and 1930: the \\ scope of the phenomenon and its ambiguous meaning
}

\section{La omnipresencia del arte religioso en la educación metodista cristiana en Brasil entre 1890 y 1930: el alcance del fenómeno y su ambiguo significado}

\author{
Helmut Renders* \\ Kalindy Hyandra Fiorio*
}

\begin{abstract}
RESUMO
Este artigo tem dois objetivos: chamar a atenção para a existência de uma cultura visual evangélica no protestantismo de missão desde a sua chegada ao Brasil, apresentando a sua riqueza e refletindo sobre como isso contribui para a nossa compreensão do protestantismo brasileiro entre 1890 e 1930 . Para isso, são estudadas 147 imagens encontradas em um Trabalho de Conclusão de Curso de Buonaduce do ano de 1941, na tentativa de entender melhor a cultura da sua distribuição e a extensão do fenômeno, bem como o seu significado. Visto que se trata de uma ampla divulgação da arte religiosa, basicamente ocidental, porém, interconfessional, com uma ênfase em artistas do século 19, seguido de artistas dos séculos 16 e 17 e, finalmente, do século 18. O elemento transversal de todas as referências parece ser sua ênfase em uma relação afetiva para com Deus - um favorecimento de uma religião de encantamento - promovida justamente por "veículos visuais", entretanto, com uma abertura inicial que transcende a dimensão de uma religiosidade do interior da pessoa humana e começa a sinalizar uma sensibilidade com a dimensão pública, social ou o aspecto exterior da religião.

Palavras-chave: Linguagens religiosas; cultura visual evangélica brasileira; arte religiosa; educação cristã; Igreja Metodista.
\end{abstract}

* Professor associado 1 da Universidade Metodista de São Paulo (Umesp), no curso de bacharel em teologia e no PPG em Ciências da Religião. Contanto: helmut.renders@ metodista.br. O artigo apresenta resultados parciais do projeto regular de pesquisa FAPESP processo 2015/13737-7 [vigência 09-2017-08-2019].

** Graduanda no curso de bacharel em Teologia da Universidade Metodista de São Paulo (Umesp). O artigo apresenta, parcialmente, resultados do seu projeto FAPESP de iniciação científica processo 2018/10622-2 [vigência 09-2018 a 08-2019], orientado por Helmut Renders. 


\begin{abstract}
This article has two objectives: to draw attention to the existence of an evangelical visual culture in the Protestantism of the mission since its arrival in Brazil, showing its richness and to argue how this may contribute to our understanding of Brazilian Protestantism between 1890 and 1930. For this purpose, 147 images found in a 1941 CBT are studied in an attempt to understand better its culture of distribution, the extent of the phenomenon and its meaning. It is concluded, that this is a widespread dissemination of western but inter-denominational religious art with an emphasis on 19th century artists, followed by 16 th and 17 th century artists and finally the 18th century. The cross-section of all references seems to be their emphasis on an affective relationship with God, a favoring a religion of enchantment, promoted precisely by "visual vehicles," however, with an initial opening to transcend the dimension of a religiosity from within the human being and begins to signalize a sensitivity for the public or social dimension, or the outward aspect of religion.
\end{abstract}

Keywords: Religious Languages; Brazilian evangelical visual culture; religious art; Christian education; Methodist Church.

\title{
RESUMEN
}

Este artículo tiene dos objetivos: llamar la atención sobre la existencia de una cultura visual evangélica en el protestantismo de la misión desde su llegada a Brasil presentando su riqueza y reflexionar sobre cómo esto contribuye a nuestra comprensión del protestantismo brasileño entre 1890 y 1930. Las 147 imágenes encontradas en un documento de finalización del curso de Buonaduce de 1941 se estudian en un intento por comprender mejor la cultura de su distribución y la extensión del fenómeno, así como su significado. Dado que es una difusión generalizada del arte religioso básicamente occidental pero interreligioso, con énfasis en los artistas del siglo XIX, seguido de artistas de los siglos XVI y XVII y finalmente del siglo XVIII. El elemento transversal de todas las referencias parece ser su énfasis en una relación afectiva con Dios, que favorece una religión encantadora, promovida precisamente por los 'vehículos visuales', sin embargo, con una apertura inicial que trasciende la dimensión de una religiosidad interior. de la persona humana y comienza a señalar una sensibilidad al aspecto público, social o externo de la religión.

Palabras clave: Lenguajes religiosas; cultura visual evangélica brasileña; arte religioso; educación cristiana; Iglesia Metodista.

\section{Introdução}

A cultura visual evangélica brasileira é "um mundo" só recentemente mais investigado pelas ciências da religião e pela teologia, apesar de ser uma das fontes mais prováveis e duradoras da formação do imaginário religioso confessional ou denominacional de gerações. Este artigo foca na fase inicial da construção desse imaginário, caracterizado pelo uso de imagens importadas dos Estados Unidos, facilmente identificáveis pelas suas referências inglesas. Uma coletânea das fontes originais dessas imagens não parece ter sobrevivido, visto que não se encontram mais as revistas das escolas dominicais originais da época. Entretanto, as imagens apresentadas neste artigo foram encontradas no Trabalho de Conclusão de Concurso de Buonaduce (1941) que estão acessíveis no Acervo da Universidade Metodista de São Paulo, UMESP. Esse TCC contém 147 imagens colecionadas pelo autor para construir uma vida imagética de Jesus e, depois, confrontá- 
-la com evidências arqueológicas. De fato, o autor critica as litogravuras que reproduzem pinturas do século 17 ao século 19, por darem ideias não exatas da vida cotidiana de Jesus, dos seus discípulos e do povo judeu, todavia, sem questionar o uso de imagens. Ademais, este artigo não pretende discutir a sua tese, porém, trabalhar a partir da sua mensagem implícita: a habitual utilização de imagens nas escolas dominicais metodistas, isto porque ainda em 1941 foram colecionadas 147 imagens de pinturas da arte religiosa, produzidas nos Estados Unidos por agências com proximidade às igrejas protestantes da missão, e estas eram de uso costumeiro e presente na então autônoma Igreja Metodista do Brasil, tanto que estas imagens se tornaram assunto de um TCC.

Vamos apresentar e discutir as informações que essas 147 litogravuras nos trazem em duas seções. Na primeira seção, vamos olhar para estas imagens e verificar o que elas apontam em relação ao tamanho ou à extensão do fenômeno, uma vez que 147 imagens representam uma quantidade considerável. Depois de termos esclarecido a probabilidade de impacto dessas imagens sobre as pessoas, a segunda seção apresentará a autoria contida na própria imagem, assim como sua companhia publicadora - quando houver - e até mesmo outras citações nelas registradas. Logo, as informações que as litogravuras denotam expressam um contexto, vislumbrando o tipo de imaginário que fora construído na época. Aqui se abrem muitas possibilidades. Pelo fato de que se trata de reproduções da arte religiosa, vamos focar nos conteúdos religiosos, já que isso deve corresponder à intenção originária dessas pinturas e daqueles ou daquelas que as colocaram em circulação. O que essas imagens afirmam em relação a aspectos doutrinários, vertentes religiosas, entre outros? Como estas imagens construíram relações entre denominações e confissões? ${ }^{1}$

\section{A extensão do fenômeno da circulação de retratos da arte religio- sa dos séculos 17 a 19 nas escolas dominicais da Igreja Metodista Episcopal Sul, entre 1890 e 1934}

A seção presente se dedica à extensão do fenômeno da divulgação de retratos da arte religiosa dos séculos 17 a 19 nas escolas dominicais da Igreja Metodista Episcopal Sul, entre 1890 e 1934. O recorte cronológico se deve

A lista de possíveis perguntas não tem limite para as extensões de um artigo. Poderíamos continuar e perguntar também: Como as imagens representam as relações entre diferentes idades, classes sociais, povos e questões de gênero? Cada um desses temas poderia ser explorado por um TCC ou artigo próprio. 
principalmente a uma razão: todas as 147 imagens encontradas no TCC de Buonaduce (1941) foram produzidas nos Estados Unidos da América. Com isso, elas pertencem ao primeiro período da cultura visual protestante, à fase do seu surgimento, justamente caraterizada pelo fato de que chegaram ao Brasil de forma pronta. Em seguida, apresentamos dois exemplos (figuras 1 e 2). Neles, a identificação é simples, por conterem informações em inglês - o que ocorre na maioria das 147 imagens. O período entre 1890 a 1934 é delimitado pelas informações sobre a produção dessas imagens e a produção do material de educação cristã para as escolas dominicais.

Figura 1: TISSOT, James. The calling of St. James and John, [1895-1896]

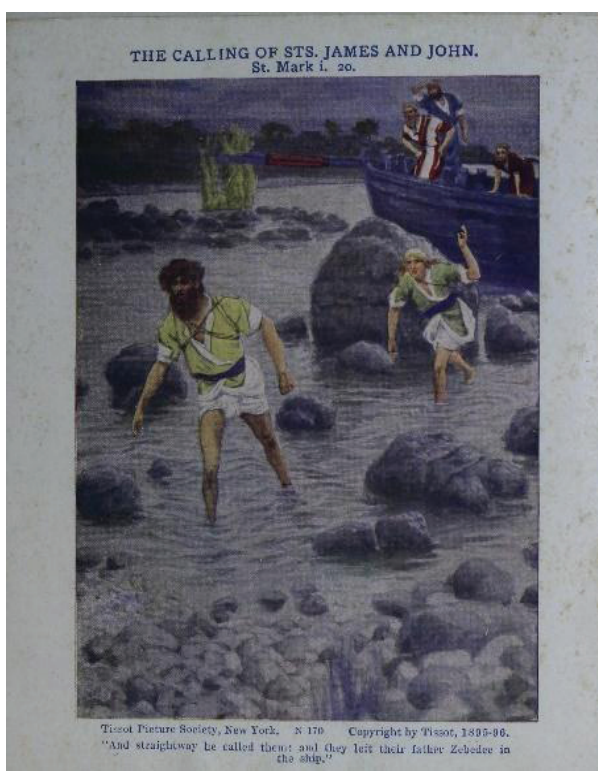

Fonte: Buonaduce, 1941, imagem 66
Figura 2: The penitent Magdalen: Florence, Uffizi, [1660-1670]'

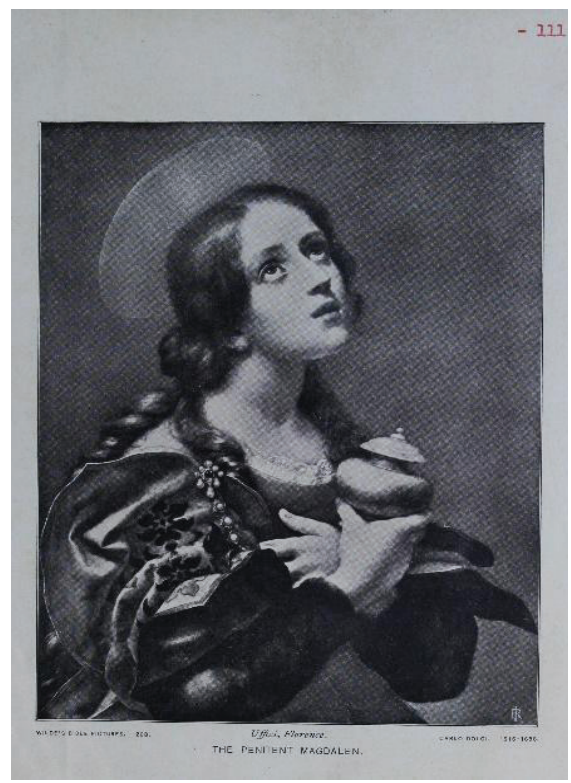

Fonte: Buonaduce, 1941, imagem 111

O ano de 1890 é uma aposta, tendo em vista que a reprodução de imagens, por exemplo, pela American Bible School Union, já havia iniciado no começo do século 19. Conquanto a criação do sistema das escolas dominicais e respectiva demanda de material educacional específico para a Igreja Metodista é datada a partir de 1850, já que a missão metodista se instalou definitivamente no Brasil em 1867, e fora oficializada em 1887, por conseguinte, a escolha do ano de 1890 parece-nos adequada. Isso corresponde razoavelmente bem às informações sobre a disponibilidade de

I Uma versão colorida encontra-se em: https://pt.wikipedia.org/wiki/Ficheiro:\%22Mary_ Magdalene\%22_by_Carlo__Dolci.jpg. 
imagens da arte religiosa. A Igreja Metodista no Brasil (autônoma desde 1930) junto a outras igrejas protestantes de missão - como os presbiterianos - começa, em 1934, a produção de seus próprios cadernos para as escolas dominicais. Supomos que, depois disso, a importação de material dos EUA diminuiu e eventualmente parou. ${ }^{2}$

A data do TCC, o ano de 1941, funciona quase como uma data post quem do seu uso, porque ela sinaliza tanto a presença das imagens no cotidiano das igrejas, como um debate sobre sua utilidade para a educação cristã. Nada obstante, como já mencionamos anteriormente, não se trata apenas da fácil circulação das imagens nas igrejas metodistas, mas o que elas informam acerca da época de Jesus. A seguir, é apresentada, para melhor compreensão, uma tabela com as casas publicadoras registradas nas litogravuras em ordem alfabética:

\begin{tabular}{|l|l|c|}
\hline Número & Casa publicadora & $\begin{array}{l}\text { Imagens } \\
\text { encontra- } \\
\text { das }\end{array}$ \\
\hline 1 & American Tissot Society, New York & 10 \\
\hline 1.1 & Copyright by Tissot, 1895-96 & 25 \\
\hline 2 & Bible Study Publishing Co., Boston & 15 \\
\hline 3 & Brown's Famous Pictures & 5 \\
\hline 3.1 & Copyright by Brown & 24 \\
\hline 4 & Union Press / The Union Bible Pictures Philadelphia & 6 \\
\hline 5 & Wilde's Bible Pictures & 1 \\
\hline 5.1 & Copyright W.A. Wilde Co. Boston & \\
\hline
\end{tabular}

Das 147 imagens, 91 apresentam a descrição da casa publicadora explicitamente. Podemos distinguir cinco fontes que publicaram coletâneas próprias: American Tissot Society, New York; Bible Study Publishing Co., Boston; Brown's Famous Pictures; Union Press / The Union Bible Pictures Philadelphia; e, Wilde's Bible Pictures. Além disso, três delas estenderam os direitos de publicação das suas imagens para outras editoras.

Que estas editoras mantiveram certamente mais imagens em circulação do que as 147 encontradas é fato, pois se conclui, a partir da numeração de

2 Podemos aqui trazer ainda mais cinco razões referentes a diminuição e, posteriormente, o encerramento das importações de imagens. Primeiro, a busca da objetividade: há o avanço da fotografia que em dicionários bíblicos se tornam referências para os cenários bíblicos [topografia, ruínas etc.]. Segundo, o questionamento de certas subjetividades: houve uma crescente sensibilização pelo aspecto apologético das imagens, especialmente daquelas criadas nos séculos 17 e 18. Terceiro, há uma sensação estética: especialmente a estética da arte religiosa do século 19, como sua estética romântica e pouco "realista", não era mais considerada adequada para o mundo depois da I Guerra Mundial. Quarto, uma condição econômica: mesmo que as novas técnicas de reprodução barateassem os custos, depois de 1928 era muito mais difícil comprar estas imagens. Quinto, o dado da efervescência nacional: contribuiu também para essa mudança a fase mais nacionalista do Brasil que, por sua vez, propiciou a autonomia da Igreja Metodista. 
série encontrada em algumas litogravuras, uma numeração mais elevada. Como exemplo, veja-se a imagem de número 195 do TCC de Buonaduce (1941), referenciada à casa publicadora Brown's Famous Pictures, apresentando o título "O sepultamento", datada em 1559, de autoria do artista italiano Ticiano Vecellio De Gregorio (1477-1576) (figura 3). A imagem de Ticiano tem o número de série 1709, mas a coletânea completa, segundo o catálogo de Brown's Famous Pictures (cerca de 1924) contava com mais do que 3.000 imagens. $^{3}$

Figura 3: Titian. O sepultamento, $1559^{\mathrm{II}}$

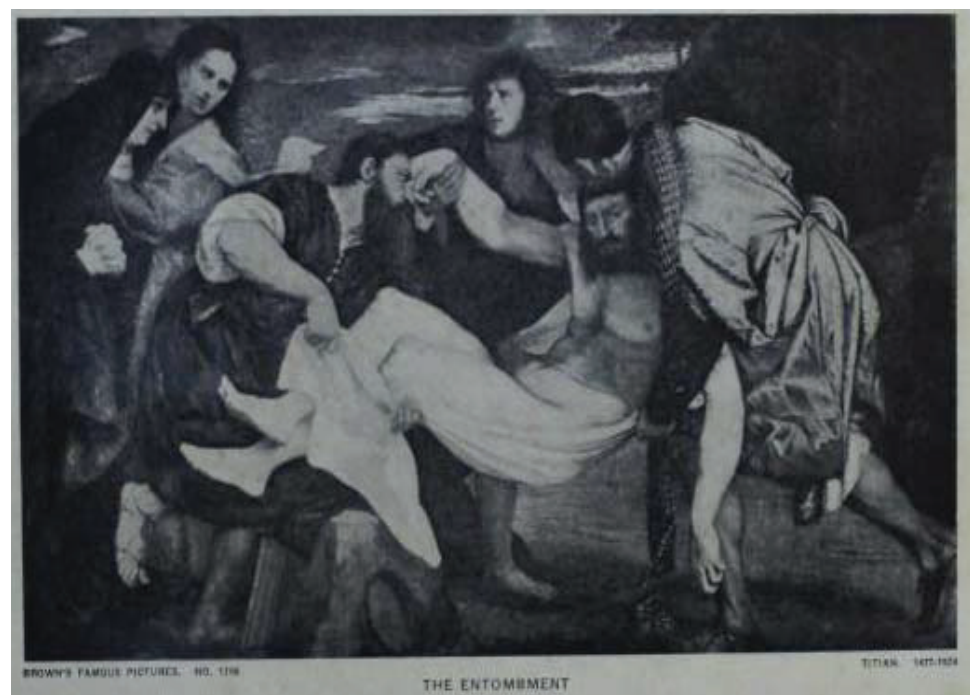

Fonte: Buonaduce, 1941, imagem 195

Além disso, encontramos outro catálogo de uma das casas publicadoras relacionadas, a saber, a editora Wilde's Bible Pictures (figuras 4 a 6). Esse catálogo de imagens está organizado por temas a respeito da vida de Jesus. Ainda assim, há neste mesmo catálogo uma série de "Madonas". Ressalta-se ainda o uso das imagens "na escola dominical e em casa" (figu-

3 A imagem menciona a casa publicadora que possui um catálogo de 48 páginas com as reproduções de "2000 imagens no tamanho regular $(12.9 \mathrm{~cm}$ x 20,3 cm); 825 imagens no tamanho miniatura $(7.2 \mathrm{~cm} \mathrm{x} 8.2 \mathrm{~cm}) ; 110$ imagens no tamanho grande $(22,8 \mathrm{~cm} \mathrm{x}$ $30.4 \mathrm{~cm})$ "; 110 imagens em platinoprints; 110 imagens em carbonprints; 28 imagens com Wall Pictures" (BROWN, S.A.).

II A obra original executada em óleo sobre tela tem as dimensões de 136x175 cm e encontra-se hoje no Museu do Prado, Madri, Espanha. Essa foi encomendada a Ticiano pelo rei espanhol Filipe II. Uma versão colorida encontra-se em $<$ https://en.wikipedia. org/wiki/The_Entombment_(Titian,_1559) >. Ticiano pintou o quadro na época do Concílio de Trento, realizado entre 1545 e 1563. 
ra 5). Todas as imagens são numeradas e o total das imagens apresentadas é de 787. O catálogo não tem uma data de publicação. Estima-se que ele seja das primeiras duas décadas do século 20. Além do catálogo acima citado, a editora publicou também, em 1916, um compêndio de 60 imagens, representando principalmente acontecimentos bíblicos (Cf. WILDE'S BIBLE PICTURES, S.A., 1915-1916). ${ }^{4}$ Estas imagens estão parcialmente acessíveis na página da Biblioteca do Congresso Nacional dos EUA. ${ }^{5}$

Figuras 4-6: List of the Wilde Bible Pictures, sem ano, capa, p. 2, 5-6
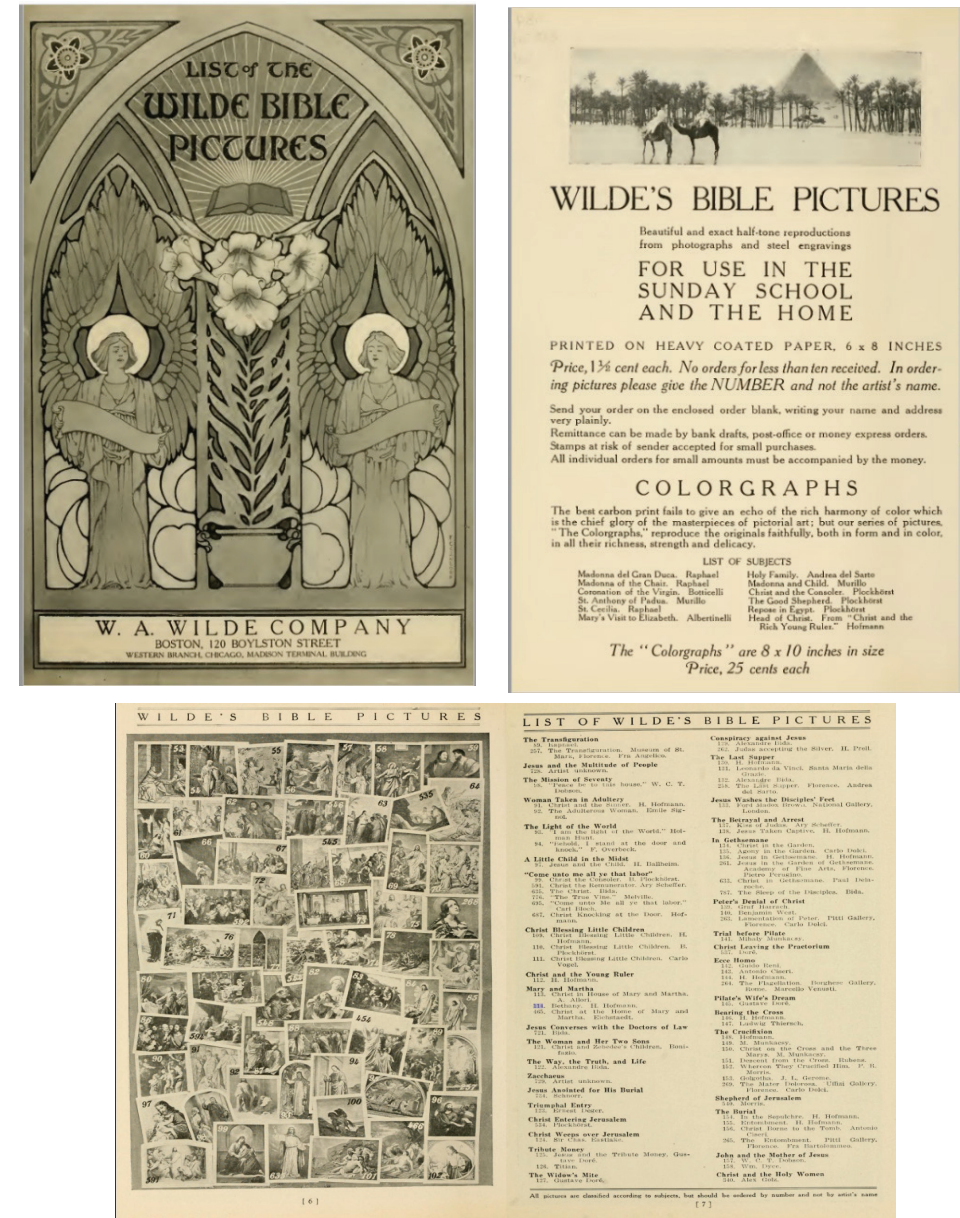

4 Disponível em: <https://www.loc.gov/item/2005692661/>.

5 A imagem número 110 do TCC e 114 do Wilde's Bible Pictures consta no catálogo da editora na página 6 . 
Num catálogo de direitos autorais referente a periódicos (Catalogue of Copyright Entries) dos EUA do ano de 1909, encontramos cadernos de escolas dominicais da casa publicadora Boston - Bible Study Publishing Company. Os cadernos seguem já na época as faixas etárias e distinguem meninos de meninas (Boys and Girls), adolescentes (Junior), jovens adultos (Intermediate) e lições introdutórias (Primary Lessons and Cards). Nesta última coletânea, chama a nossa atenção a expressão "cards", que supostamente se refere a uma parte daquelas coletâneas de imagens que foram encontradas no TCC de Buonaduce (1941). No Catalogue of Copyright Entries constam para 1909 três cadernos da Companhia Publicadora de Estudos Bíblicos de Boston - os números 47, 48 e 50. Supomos que faltou a edição 49. Como o TCC de Buonaduce (1941) contém 15 imagens dessa companhia, deve se tratar de uma dessas "quatro" edições anuais. As duas editoras venderam, então, 60 imagens por ano, que deve representar o formato comum.

Visto o conjunto de casas publicadoras, a American Sunday School Union, acima mencionada como Union Press, Philadelphia ou Union Bible Pictures Philadelphia ${ }^{6}$, deve ter fornecido o maior número de imagens. Data-se o início das atividades em 1816 com centenas de publicações ${ }^{7}$, entre elas o Quarterly Sunday School Magazine - que iniciou, provavelmente, o padrão para as demais revistas - por ser mais antiga do que as outras. Assim sendo, ao observar as edições de "cards" percebem-se semelhanças com a publicação acima citada.

Outro caso à parte é a publicadora American Tissot Society, New York, pelo fato de distribuir unicamente obras do artista francês James Joseph Jacques Tissot (1836-1902). Tissot era influenciado pelos impressionistas franceses, porém, mudou-se para Londres em 1870 por causa da sua participação no levante da comuna de Paris, durante a Guerra entre a França e a Prússia, sendo considerado um comunista. Em Londres, Tissot teve sucesso pelos seus retratos de membros das classes altas, especialmente de mulheres. As suas pinturas religiosas são datadas dos seus últimos 20 anos de vida, que se originaram a partir de 1882, depois da morte de sua parceira. Em duas viagens para a Palestina, ele produziu cerca de 700 pinturas com temas da vida de Jesus (COLI, 2019).

6 Não conseguimos esclarecer se The Union Bible Pictures é da mesma fonte, já que não consta entre as publicações da Online Books by American Sunday School Union na página The Online Book page.

7 Cf. "Online Books by American Sunday School Union”. In: The Online Book page. Disponível em: < http://onlinebooks.library.upenn.edu/webbin/book/ lookupname?key=American\%20 Sunday\%20 School\%20Union $>$. Acesso em: 21 fev. 2019. 
Vamos, então, para o possível número de imagens em circulação. Uma forma possível seria somar as séries das casas publicadoras encontradas. Podemos inferir os números 700 à Tissot, 778 à Wilde e 2000 à Brown's Famous Pictures. Supomos que a casa publicadora Wilde's Bible Picures pretendesse vender 60 imagens por ano, como foi citado anteriormente, e representasse um padrão. Tendo em vista que um ano tem, em média 52 semanas, inclusive dias festivos como Natal, Semana Santa e Pentecostes, o material de Brown poderia ser usado durante 33 anos; de Wilde ${ }^{8}$, por cerca de 13 anos; e Tissot por, aproximadamente, 12 anos; sem repetir ao menos uma só imagem. Entretanto, mesmo considerando uma certa circularidade ou duplicidade pelos copyrights, Tissot, Wilde e Brown juntos somariam 3.487 imagens, o que superaria o montante de 2.640 imagens, de atividades contínuas, entre 1890 a 1934 se tivessem publicado 60 litogravuras por ano (44 anos x 60 imagens $=2.640$ imagens). Uma pessoa que entrou na escola dominical ainda criança e, posteriormente, trabalhou como professor ou professora da mesma durante anos, supostamente teria acesso, sem esforço nenhum, a cerca de 300 a 600 litogravuras ou mais. ${ }^{9}$ Concluímos, portanto, que as reproduções da arte religiosa em circulação nas escolas dominicais da Igreja Metodista foram por quarenta anos algo costumeiro.

\section{As características dos retratos da arte religiosa dos séculos 17 a 19 que circularam nas escolas dominicais da Igreja Metodista Episcopal Sul, entre 1890 e 1934}

Nesta segunda seção, olhamos para os artistas e os motivos das imagens. Primeiro, chama a atenção que a maioria das imagens contêm informações sobre os artistas e o nome original da obra. Isso se repete também nos catálogos.

Os dois catálogos encontrados - Brown e Wilde - contêm listas de todas as suas imagens com o nome da pintura e do artista que a criou. $\mathrm{O}$ catálogo Brown's Famous Pictures, de 1924 (figura 7), demonstra que, além do conteúdo específico de cada imagem e do significado conjunto das séries temáticas, um critério da escolha era o grau de reconhecimento dos artistas e se refere a "belas reproduções fotográficas das pinturas dos grandes mestres, antigos e modernos; muitas amostras de todas as escolas de arte, incluindo todas as pinturas mundialmente famosas" (figura 7). Interessantemente, não se falava de igrejas ou de vertentes espirituais. Pelo contrário, tanto Brown como Wilde, cujas imagens foram encontradas no TCC de 1941, têm, além de séries da vida de Jesus, também séries com madonas.

\footnotetext{
8 As publicações de Wilde são até hoje reeditadas (WILDE, 2018).

9 Alguns devem ter colecionado as imagens também.
} 


\section{BROWN'S FAMOUS PICTURES}

Beautiful Photographle reproductions of the paintings of the great masters, both old and modern; many specimens of every school of art, comprlsing all the world-famous paintings. Also Portralts of Famous Men and Women, Statesmen, Authors, Inventors, Generals, Composers, Artlsts, and their homes; Famous Buildings. Catbedrals, Arebitecture snd Beulpture: several hundred Rellglous Pletures, 350 illustrating the Life of Christ; 300 Madonnas by the great masters; Thanksgiving and Christmas Pictures; Musical Pictures: Easter Pictures; Historical Pictures for every month in the year; all the Presidents of the United States.

For use in Kindergarten. Primary. Grammar and High Schools. For Pieture Study, Language. Literature and School-room Decora-
Filler thon. For Art Colleetions.

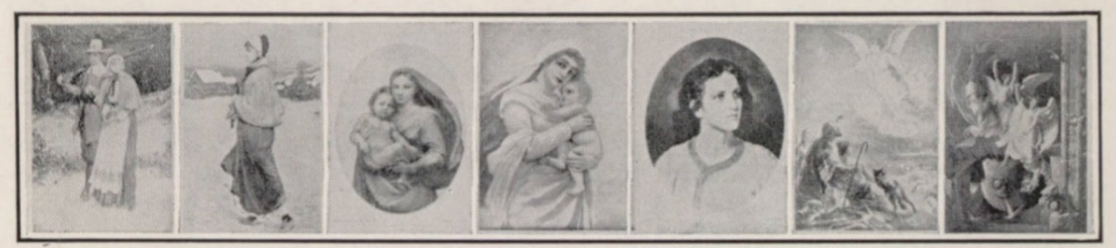

THANKSGIVING AND CHRISTMAS PICTURES

Regular Size 5 1-2 × 8. $\$ 1.50$ per 100 or 1 1-2 cents each in lots of 20 or more. Less than 20,2 cents each postpaid.

Fonte: https://hdl.huntington.org

Também retratos de homens e mulheres famosos, estadistas, autores, inventores, generais, compositores, artistas e seus lares; edifícios famosos, catedrais, arquitetura e escultura; várias centenas de pinturas religiosas, 350 ilustrando a vida de Cristo e 300 Madonas pelos grandes mestres. Pinturas de ação de graças e natal; pinturas de música; pinturas de páscoa; quadros históricos para todos os meses do ano; quadros de todos os presidentes dos Estados Unidos (BROWN, cerca de 1924).

No caso de Wilde, as Madonas também são o grupo principal de imagens maiores e coloridas: no tamanho de $10,32 \mathrm{~cm} \times 25,40 \mathrm{~cm} .{ }^{10} \mathrm{O}$ programa de cinco madonas, dois santos e quatro retratos de Cristo e a escolha dos artistas dessas 11 imagens transcendem confissões e reúnem quatro pintores italianos católicos renascentistas: Rafael Sanzio (14831520), Sandro Botticelli (1445-1510), Mariotto di Bigio di Bindo Albertinelli (1474-1515), Andrea del Sarto (1486-1530); um pintor espanhol católico barroco, Bartolomé Esteban Murillo (1617-1682); e dois pintores protestantes, Berhard Plockhorst (1825-1907) e Heinrich Johann Ferdinand Hofmann (1824-1911), com forte influência no movimento nazareno - uma escola do romantismo alemão sob influência dos pré-rafaelitas ingleses. ${ }^{11}$

\footnotetext{
$108 \times 10$ inches.

11 COLORGRAPHS. A melhor impressão de carbono não dá eco da rica harmonia de cores, que é a principal glória das obras-primas da arte pictórica; mas nossa série de imagens "The Colorgraphs" reproduzem fielmente os originais, tanto na forma, como na cor, em toda a sua riqueza, força e delicadeza. LISTA DE ASSUNTOS: Madonna del
} 
Todos estes artistas e muitos outros encontramos também no catálogo de Brown. Ao estudar a vasta lista dos variados artistas que compõem os catálogos, podemos identificar ênfases distintas, como pode ser verificado na lista dos 12 Colorgraphs de Wilde.

A primeira ênfase está atrelada aos artistas clássicos mais referenciados, que são da época da Renascença, no fim do século 15 até depois de 1517, ou da época da Reforma Protestante.

Figura 8: DA VINCI, Leonardo. A última ceia, 1495-1498

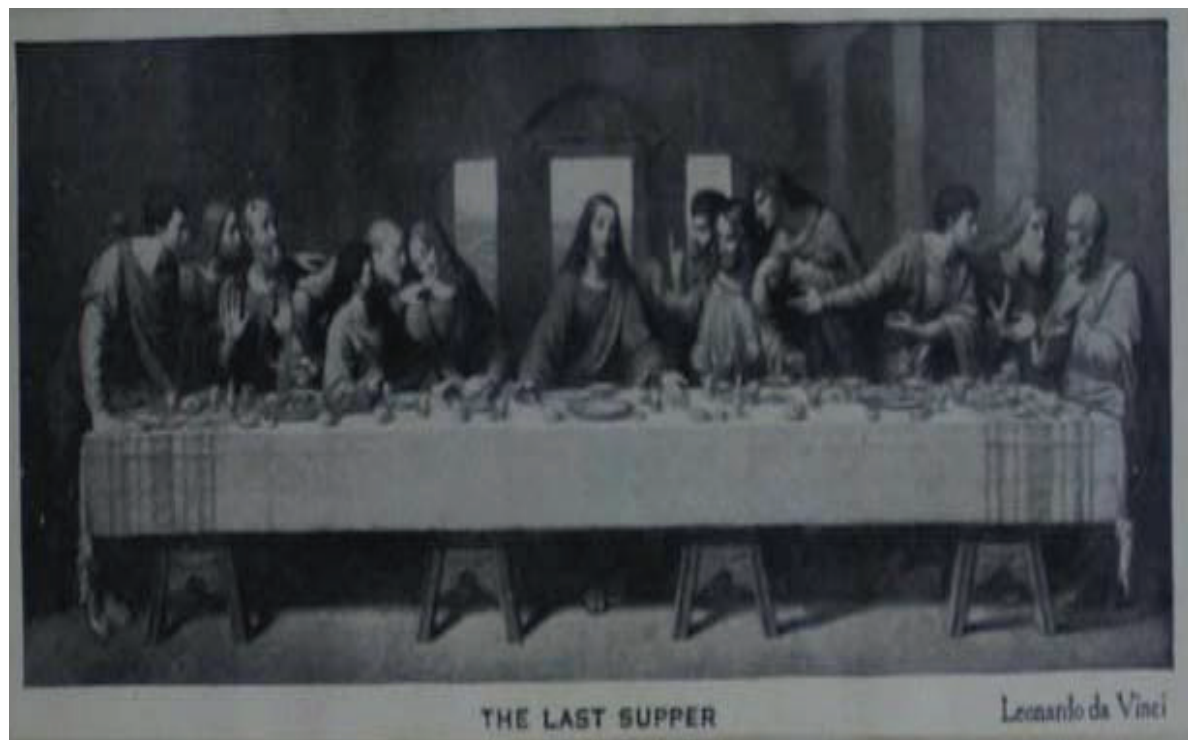

Fonte: Buonaduce, 1941, imagem 168

A segunda ênfase pertence claramente aos artistas do século 19, novamente sem distinção confessional, como demonstram os dois artistas mais requisitados, tanto por Wilde como por Brown, o francês católico Paul Gustav Doré (1832-1883) e o alemão protestante Heinrich Ferdinand Hofmann (1824-1911). ${ }^{12}$ Tanto Doré como Hofmann eram muito famosos

Gran Duca. Rafael; Madonna da Presidência. Rafael; Coroação da Virgem, Botticelli; Santo Antônio de Pádua, Murillo; Santa Cecília, Rafael; A visita de Maria a Elizabeth. Albertinelli; Família sagrada. Andrea del Sarto; Madonna e criança. Murillo; Cristo e o consolador. Plockhorst; O bom Pastor, Plockhorst; Repouse no Egito. Plockhorst; Cabeça de Cristo de "Cristo e o Jovem Governante Rico", Hofmann.

12 O catálogo de Brown contém 61 imagens de Doré e 31 de Hofmann. Logo em seguida vem Berhard Plockhorst. Há no mínimo uma publicação que foca em imagens tanto de Hofmann como de Plockhorst (STROTON, 1992). 
na sua época e reconhecidos muito além dos círculos da sua atuação inicial. Ou seja, os dois são exemplos da busca por excelência pelas casas publicadoras, inclusive entre os artistas do século $19 .{ }^{13} \mathrm{O}$ francês Doré, pintor e desenhista, é considerado o ilustrador francês de livros mais produtivo e bem-sucedido ou famoso de meados do século 19 .

Figura 9: Doré, Gustavo. Jesus and the woman of Samaria, Brown's Famous Pictures, [1885]

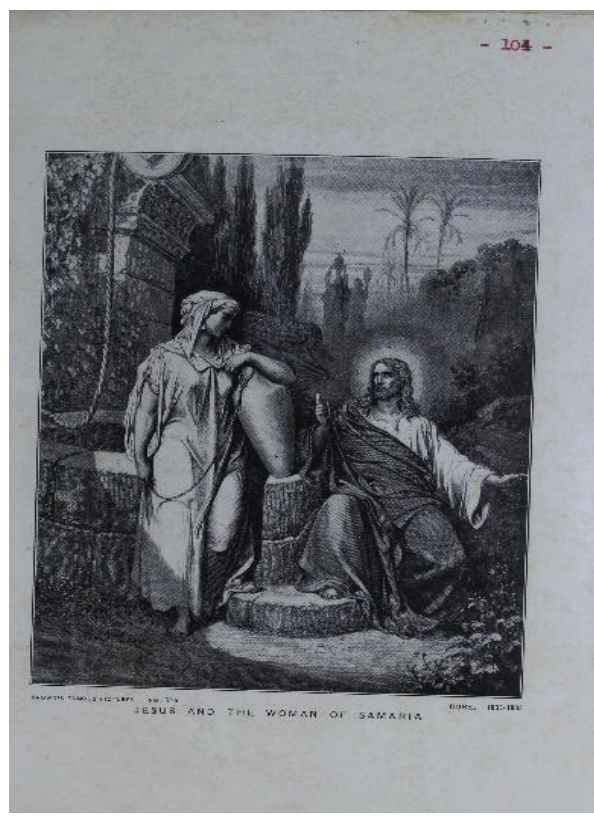

Fonte: Buonaduce, 1941, imagem 104
Figura 10: Hofmann, Heinrich F. Anointing of Jesus by Mary. Philadelphia: Union Press, [1900].

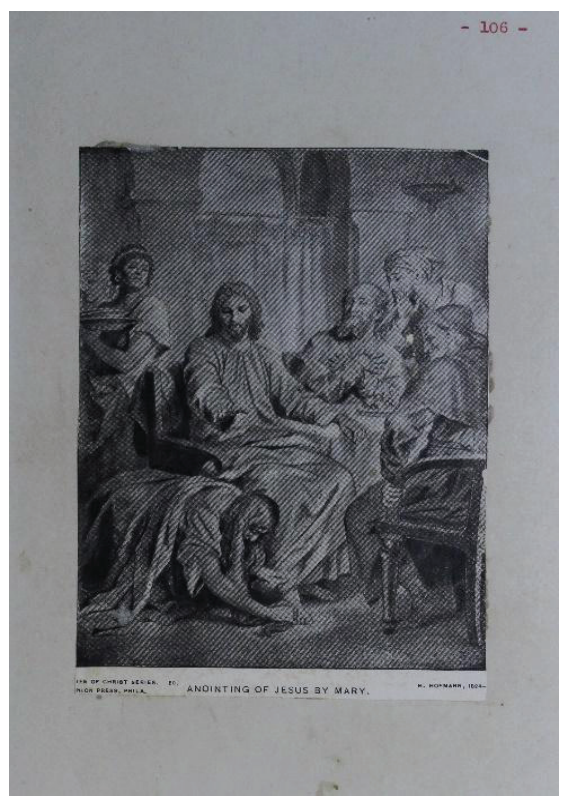

Fonte: Buonaduce, 1941, imagem 111

Suas ilustrações se concentram em três gêneros: livros fantásticos ${ }^{14}$, estudos sobre as áreas pobres de Londres (1869-1871) ${ }^{15}$ e imagens com temas bíblicos (1866), inicialmente criadas para uma edição francesa da Vulgata $^{16}$, ou seja, uma edição católica da Bíblia cuja tradução se baseia no

13 Aqui as casas publicadoras protestantes seguiram a tradição jesuíta que também reuniram os melhores artistas da sua época para seus livros com emblemas nos séculos 16 e 17.

14 Münchhausen de Gottfried August Bürger (1862) com 158 ilustrações; Dom Quixote de la Mancha de Miguel de Cervantes (1863) com 377 ilustrações; O Paraíso Perdido de Milton (1866); O Corvo, de Edgar Allan Poe (1882).

15 Mas também uma obra de Vitor Hugo (Les travailleurs de la mer, 1867, cm 22 ilustraçoes).

16 Disponível em: <https://en.wikipedia.org/wiki/Gustave_Dor\%C3\%A9\%27s_illustrations_for_La_Grande_Bible_de_Tours $>$ 
texto em latim e não hebraico/aramaico e grego koiné. ${ }^{17}$ São estas imagens da edição católica que, pela sua qualidade, fizeram também muito sucesso nos Estados Unidos e chamaram a atenção das casas publicadoras protestantes que as reproduziram em grandes quantidades. ${ }^{18}$ Especialmente no exterior, no mundo anglo-saxão, Hofmann era considerado um dos grandes pintores alemães da sua época: basta verificar seus retratos de Cristo amplamente divulgados até em coletâneas especiais (cf. HOFMANN, 1888; STRETTON, 1891; GRABNER \& HOFMANN, 1900-1914). Alguns destes retratos se tornaram ícones do protestantismo nos dois lados do atlântico, como, por exemplo, a sua pintura "Jesus no jardim de Getsêmani", encontrada atualmente na Riverside Church, uma Igreja Batista em Nova Iorque. ${ }^{19}$ Hofmann é considerado membro da escola romântica, mas se inspirou muito na linguagem artística dos mestres renascentistas. De certo modo, amalgama em sua estética artística o primeiro grupo de destaque de artistas dos séculos 15 e 16 com o grupo de artistas do século 19.

O terceiro grupo mais referenciado pelos catálogos são os artistas católicos maneiristas, como os italianos Ticiano (1477-1576) e Tintoretto (1518-1594); e barrocos, como os espanhóis Velázquez (1599-1660) e Morillo (1617-1682); e os italianos Annibale Carracci (1560-1609) e Carlo Dolci (1616 -1686). Os pintores do século 17 são expressivis verbis articuladores da reforma católica, ou seja, da contrarreforma. Aparentemente, temos aqui uma apreciação estética e não confessional no sentido doutrinário ou das políticas eclesiásticas, já que há elementos que a linguagem artística barroca (séculos 17 e 18) e a linguagem romântica (século 19) compartilham: a ênfase no afeto, na comoção, no encantamento, no mundo interior do ser humano em vez do seu mundo exterior, como movimentos que procuram superar impasses mais racionais da religião.

$\mathrm{O}$ que na reforma católica se apresenta como uma estratégia para conter os avanços do protestantismo, aparece no protestantismo paralelamente ao tempo da reforma católica como um movimento que se opõe à ortodoxia protestante, movido pelo pietismo (luterano), metodismo (anglicano) e

17 Edição recente da bíblia Doré: The Holy Bible: King James Version (Leather-bound Classics) Leather Bound - October 22, 2013 by Paul Gustave Dore (Illustrator), Richard Rothschild (Designer).

18 Inclusive em forma de uma Bíblia da Família Ilustrada protestante que chegou com missionários estadunidenses ao redor da virada do século 19 para o século 20 no Brasil (FOSTER, 1890). A primeira edição dessa bíblia é de 1873 ou seja, as gravuras de Doré da edição da Vulgata já foram sete anos depois usadas em uma edição protestante.

19 No Catalogo de Wilde (1924, p.7) aparece como imagem "136. Jesus in Gethsemane. H. Hofmann" e no catálogo de Brown (1924, p. 5) como imagem "219 Christ in the Garden of Gethsemane, Hofmann". 
puritanismo (reformado), que depois se desdobra no romantismo, mesmo que sob novas exigências. ${ }^{20}$

Um olhar panorâmico referente aos pintores é interessante, especialmente, pelas suas ênfases em artistas específicos do século 19, ao lado do encanto e do compromisso social. Este é certamente o caso nas obras do católico Gustav Doré (1832-1883) e do protestante Ford Madox Brown (1821-1893), ambos artistas transitaram entre motivos religiosos e motivos sociais. Doré pela obra "Londres: uma peregrinação", da qual demostramos, em seguida, o motivo dos "sem teto" (figura 11).

Figura 11: Doré, Gustavo. "Roofless". In: London: a pilgrimage, 1872. In Chapter XV, 1862

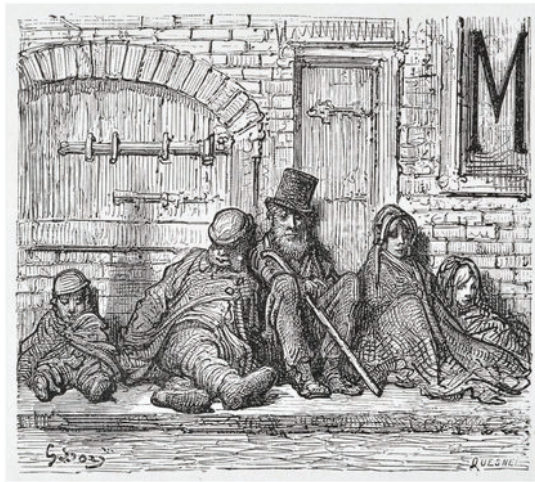

Fonte: www.museumoflondonprints.
Figura 12: Brown, Ford Madox. Christ washing Peter's feet. [s.l. / s.e. / s.a.]

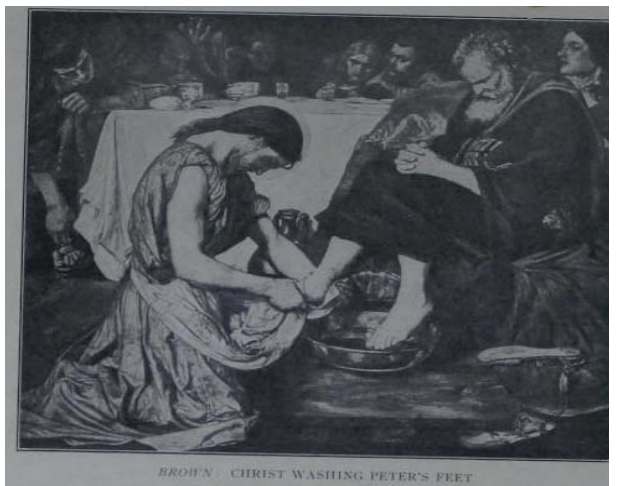

Fonte: Buonaduce, 1941, imagem 167 com

E Brown com a litogravura "Cristo, lavando os pés de Pedro" tem, por sua vez, uma interessante história de criação e recriação. A pintura original apresenta Cristo sem camisa, parecido com um trabalhador braçal. ${ }^{21}$ A obra não se vendeu. Depois, Brown refez a obra duas vezes: em uma delas, Jesus é apresentado com uma veste com mangas longas, porém arregaçadas até o antebraço; em outra, com a manga arregaçada até os ombros. Esta última versão acompanha a iconografia dos trabalhadores em sua obra mais famosa, "O trabalho", que existe em uma versão de

20 Note o uso do título Pia desideria, o que significa desejos piedosos, tanto pelo seu inventor, o católico e belga Herman Hugo (1624), o luterano e pietista hessiano Philip Jakob Spener (1676) como pelo puritano da Nova Inglaterra, América do Norte, Cotton Mather (1722) [e conhecido pela sua ligação com a caça às bruxas de Salém, Massachusetts, em 1692]. As três obras são guias espirituais consagrados e de referência para seus pares.

21 Cf. https://paintingandframe.com. 
Manchester e uma versão de Birmingham, Inglaterra. Aqui se observe que os três trabalhadores homens retratados no centro também apresentam os braços descobertos, como Jesus na pintura anterior (figura 12). A sensibilidade romântica e religiosa é, então, não meramente focada no interior da experiência religiosa ou do experimentar religioso. Justamente os artistas famosos como Doré (1872, 1907; VOLTAIRE, 1915) e Brown eram conhecidos pelas suas opções sociais pelas quais, inclusive, foram criticados por seus contemporâneos europeus que pertenciam às classes sociais mais elevadas (e que visitaram as exibições dos artistas para comprar as suas obras). ${ }^{22}$

Figura 13: Brown. “Work”. In: Birmingham, 1893

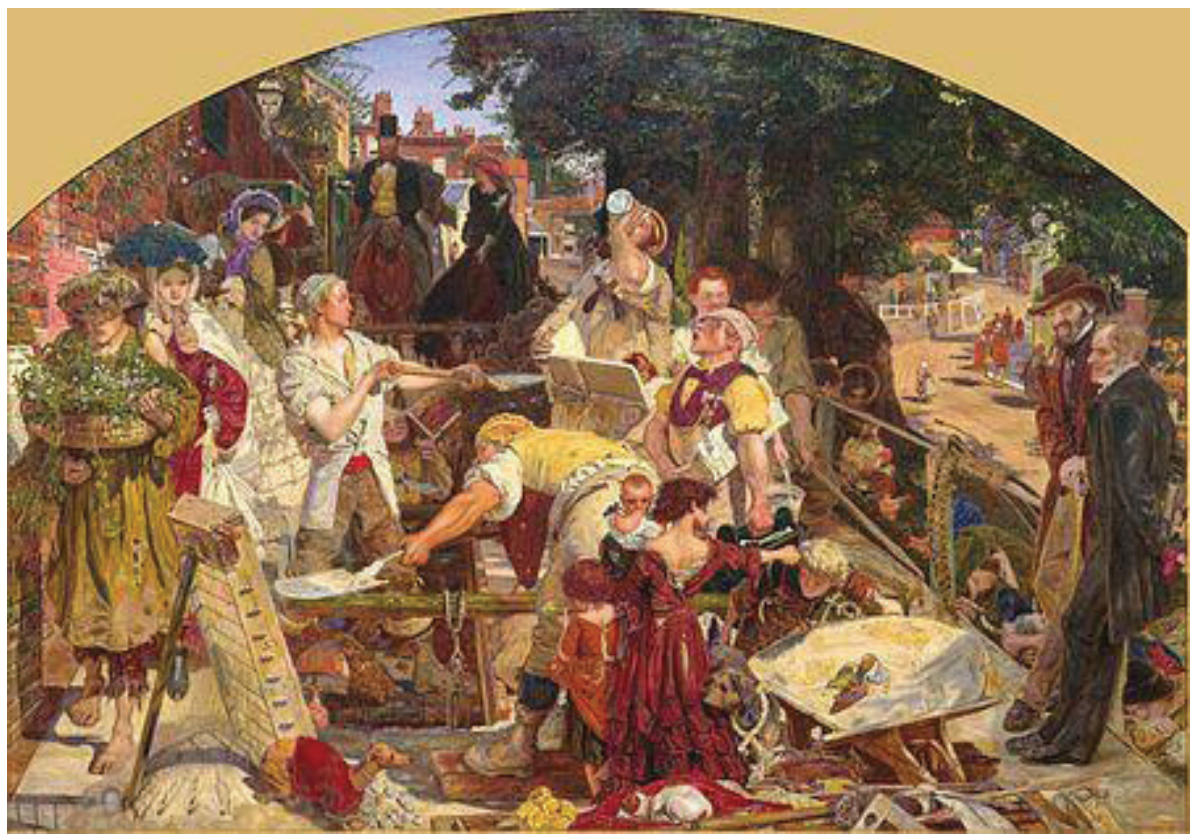

Fonte: www.wikipedia.org

22 Considerando o acervo da Biblioteca Nacional do Brasil no Rio de Janeiro, houve um amplo interesse nas publicações de Gustave Doré, tanto nas linguagens originais como com nas traduções para o português. As suas ilustrações de Dante existem em 11 edições, a primeira de 1887 . Também se encontram as ilustrações religiosas, tanto como Bíblias completas, quanto em folhas soltas (DORÉ, 1976). Doré era e é, ainda hoje, prestigiado no Brasil, e as imagens "protestantes" fizeram a sua arte conhecida entre as classes mais humildes da sociedade. 
Nas imagens circuladas nas escolas dominicais estadunidenses, entretanto, este novo olhar dos artistas aos centros da industrialização mais desenvolvida - Manchester deu até um nome a um típico capitalismo e Londres era o centro financeiro e seu promotor mundial - está discretamente presente e sinaliza a possibilidade de uma nova síntese entre experiência religiosa e compromisso social religioso, um movimento encantado por Deus que não ia virar as costas aos miseráveis da sua época, um pré-anúncio do casamento entre as vertentes mais conservadores e progressistas, tanto no socialismo religioso inglês, como no socialismo cristão alemão, suíço e francês e, especialmente, como no evangelho social estadunidense entre 1860 e $1920 .{ }^{23}$

Uma observação final em relação às casas publicadoras identificadas no TCC de Buonaduce (1941) parece ainda importante: todas elas eram localizadas nos estados da costa leste dos EUA que pertenciam à antiga união, não aos estados da antiga confederação. ${ }^{24}$ Portanto, mesmo que a Igreja Metodista Episcopal Sul, que foi a Igreja Matriz do coração do metodismo brasileiro, tenha se reunificado com a Igreja Metodista Episcopal em 1939 para formar a Igreja Metodista Unida, podemos dizer que o material da escola dominical dessa igreja do sul e da sua missão brasileira

23 Não é a nossa ênfase, mas merece ser mencionado que nós encontramos recentemente, na Biblioteca Nacional do Brasil no Rio de Janeiro, um exemplar das Histórias do Evangelho e da arte, de John La Farge (1913). Nesta edição, com 80 imagens, o autor e artista segue uma organização parecida dos catálogos de Brown e Wilde, porém, La Farge usa somente pinturas de artistas católicos. La Frage era católico, mas foi chamado para criar vitrais, especialmente em igrejas protestantes. Suas obras mais famosas se encontram em oito igrejas anglicanas [Trinity Church, Boston (1877-78); Church of St. Joseph of Arimathea in Greenburgh, New York (1883); The Cathedral of All Saints, Albany, New York; Unity Church of North Easton, Massachusetts (1882 St. Paul's Chapel, Columbia University, NYC (1888-99); Trinity Episcopal Church in Buffalo, New York (1886-89); All Saints Episcopal Church, Briarcliff Manor, New York (1889); Church of the Transfiguration, Episcopal, New York City (1898); duas Igrejas Unitárias [First Unitarian Church of Detroit (1890); First Unitarian Church of Philadelphia (1891)], uma Igreja Congregacioanlista [Mount Vernon Church, Boston, 1890], uma Igreja Batista [Judson Memorial Church ] e uma Igreja Metodista [First United Methodist Church of Columbia, TN] e uma única Igreja Católica [Our Lady of Mercy Chapel at Salve Regina University in Newport, Rhode Island]. Um dos seus filhos, John La Farge Jr., S.J. (1880-1963), se tornou jesuíta e se posicionou fortemente contra o antissemitismo e o racismo. O livro de La Farge foi reeditado nos EUA, em 1926. O livro evidencia também que houve artistas católicos apreciados por protestantes.

24 Do Norte para o Sul: Beverly, Massachusetts (Brown's Famous Bible Pictures), Boston, Massachusetts (Bible Study Publishing, Wilde's Bible Pictures), Nova Yorque (American Tissot Society) e Filadélfia, Pensilvânia (Union Press). A cidade de Filadélfia fica ainda $450 \mathrm{~km}$ distante da capital do Sul, Richmond, Virginia. 
era "do norte" e não "do sul" 25 ; do norte industrializado e não do sul rural. Como o trabalho com as imagens nas escolas dominicais começou já na União da Escola Dominical Americana em 1816, e a divisão ocorreu em 1844 , supomos que as imagens "do norte" não foram vistas no sul como imagens "dos outros", ou algo estranho, mas como parte de uma cultura visual protestante à qual as duas vertentes metodistas pertenciam independente das escolhas econômicas e políticas, já que o material aqui estudado foi encontrado em um acervo de uma das missões da Igreja Metodista Episcopal Sul. Neste caso, a cultura visual compartilhada teria contribuído para a contínua construção de um imaginário religioso compartilhado, em tempos antes, durante e depois da divisão do corpo eclesiástico. E diríamos mais: unindo essa informação com aquela sobre a escolha de artistas, podemos inferir que a cultura visual protestante que chega no Brasil era, em potencial, uma cultura visual protoecumênica, visando não a divisão, mas, sim, a cultura visual em comum.

\section{Considerações finais}

O propósito inicial desse trabalho foi abrir mais uma porta para verificar a importância da cultura visual na formação do protestantismo de missão no Brasil, especialmente entre metodistas e presbiterianos, mas também, congregacionais e até batistas, mesmo que mais pontualmente. Para tanto, a nossa investigação focou tanto aspectos quantitativos como qualitativos. Os aspectos quantitativos não deixam dúvida de uma alimentação contínua do imaginário religioso protestante pela arte religiosa europeia, em geral, ocidental. ${ }^{26}$ Deve-se falar de centenas, ou até mesmo milhares, de imagens que em um fluxo contínuo comunicaram os conteúdos do evangelho para uma população ainda pouco alfabetizada.

Em seguida, o que impressiona é a variedade de artistas e obras apresentadas, além dos vínculos confessionais e espirituais distintos. Entre as opções, três preferências foram percebidas: em primeiro lugar, a opção por artistas do século 19, artistas contemporâneos da época, muitos da vertente romântica, como dos Nazarenos ou dos Pré-rafaelitas, em sua maioria protestantes, ingleses e alemães, mas também minoritariamente, franceses católicos; em segundo lugar, as referências aos artistas renascentistas, inclusive do período antes da Reforma, entre os quais a questão

25 Entretanto, houve também uma produção do Sul, justamente como mostra um título de Heinrich Hofmann (1892), publicado em Richmond, Virgínia.

26 De fato, não encontramos ícones gregos ou ortodoxos, ou imagens no estilo bizantino. 
da confessionalidade não era, ainda, na sua grande parte, um assunto; finalmente, em terceiro lugar, um número ainda significativo de pintores barrocos, italianos e espanhóis, de fato comprometidos com o projeto da reforma católica, tanto como um movimento interno da Igreja Católica (posteriormente com o movimento da romanização), quanto como um projeto de construção de uma linguagem religiosa visual mais racional e, supostamente, protestante. Entendemos que os temas que transpassam essas vertentes estão atrelados ao encanto, à afetividade, às práticas de piedade que envolvem conjuntamente corpo, alma e mente; caso não trabalhem em conjunto, que a ênfase esteja abarcada no afeto.

Além disso, as casas publicadoras de Brown e Wilde demonstram suas preferências, salientadas na quantidade de obras reproduzidas por artistas como Doré. A pergunta é: a nossa compreensão de uma religiosidade afetiva no século 19 não deveria ser ampliada para além de estereótipos que reduzem encantamento ao interior do ser humano, sem considerar a possiblidade de que ela integre compaixão e vontade real a favor da transformação social? Podemos afirmar que alguns dos artistas mais requisitados, como Doré, uniram em si, e em sua obra, o olhar compassivo para o mundo ao seu redor com o encanto religioso localizado no interior do ser humano. Não temos como provar que aconteceu dessa forma no Brasil, mas podemos lembrar que, justamente no Brasil, apareceram já em 1888 fortes indícios da presença do evangelho social por meio de mudanças em textos doutrinários essenciais, no caso, os Artigos de Religião (RENDERS, 2017, p. 465-491).

Temos então, baseados nessas expressões da cultura visual, uma conclusão dupla quanto à articulação religiosa dessa cultura, em sua fase de surgimento. Por um lado, a cultura visual da época promovia o ideal da cordialidade humana de verdade, alternativa àquilo que Buarque de Holanda caracterizava pela sua adaptação da tipologia de Max Weber como tipo sociológico e antropológico brasileiro, o "homem cordial". Por outro lado, essa mensagem de fundo pode ter ficado despercebida pela sua sutilidade. Neste caso, prevaleceu a articulação de uma noção romântica da fé, aberta a expressões emocionais da religiosidade, com o potencial de ceder espaço para ênfases desproporcionais de paixão, formas teatrais dramáticas, exuberantes, enfim, barrocas da fé. Os dois caminhos estavam ambos presentes em potencial na cultura visual trazidas pelas igrejas protestantes de missão. E o século 20 veria os dois em conflito permanente. 


\section{Referências bibliográficas}

BROWN, George P. Brown's Famous Bible Pictures. Beverly, Mass, cerca de 1924 Disponível em: < https://hdl.huntington.org/digittion/p9539coll1/id/5876/ > Acesso em: 4 set. 2019.

BROWN, Ford Madox. Christ washing Peter's feet [sem camisa]. Disponível em: < https://paintingandframe.com/prints/ford_madox_brown_jesus_washing_peter\%27s_feet2884.html >, acesso em 28 de agosto de 2019.

BUONADUCE, Fernando. Os evangelhos na arte: erros de inspiração. 1941. Monografia (Graduação em Teologia). Faculdade de Teologia da Igreja Metodista. [Atualmente: Escola de Teologia da Universidade Metodista de São Paulo, São Bernardo do Campo.] COLI, Jorge. Verbete “Tissot, James”. In: Página Warburg: Banco comparativo de imagens. Disponível em; < http://warburg.chaa-unicamp.com. br/artistas/view/1319>. Acesso em: 10 fev. 2019.

DORÉ, Gustave. Versailles et Paris en 1871 d'après les dessins originaux de Gustave Doré. Prefácio de M. Gabriel Hanotaux. Paris : Plon-Nourrit et cie, 1907.

DORÉ, Gustave. A Bíblia em folhas soltas. Rio de Janeiro: Ed. Brasil-América Ltda, [1976?].

DORÉ, Gustave; JERROLD, Blanchard. London: a pilgrimage, 1872. In Chapter XV.

HOFMANN, Heinrich. The beautiful tree of life: being a collection of helpful hints and suggestions from the most eminent teachers and writers regarding the cultivation and production of the fruits of Christian living: charity, faith, hope, holiness, humility, joy, love, patience, temperance, truth, virtue, wisdom. To which are added original articles on the model Christian man, the model woman, and the model Sunday-school scholar. Richmond: B.F. Johnson, 1892.

FOSTER, Charles. Pictorial Family Bible. Philadelphia: Andrew J. Holman \& Co, 1890.

GRABNER, Theodore; HOFMANN, Heinrich. The life of Christ: according to the four Gospels. New York; Reutlingen: Ernst Kaufmann; Ensslin \& Laiblin. [1900-1914?]

HOFMANN, Heinrich. Come unto me: twelve pictures from the life of Our Lord. London, [1888]

LA FARGE, John. Gospel stories and arte: with eighty full page plates. New York: MacMillian, 1913.

LA FARGE, John. Gospel stories and arte: with eighty full page plates. Reprint. Norwood, Mass.: Northwood Press, 1926.

MARTIN, F. David. What is a Christian Painting?. In: Leonardo, v. 10 n. 1, p. 23-29, 1977.

MATHER, Cotton. Pia Desideria [flame e vital piety]. Boston, 1722. 
RENDERS, Helmut. Reconciliação como "superação de inimizade pela amizade": desenvolvimento e desdobramentos brasileiros de uma ênfase soteriológica metodista. Pistis \& Praxis, Curitiba, v. 9, n. 2, p. 465-491, abr./ago. 2017.

RENDERS, Helmut. Uma proposta de periodização da cultura visual evangélica brasileira: surgimento, abrasileiramento e metaformização glocal. Numen, Juiz de Fora, v. 21, n. 1, p. 10-37, jan./jun. 2018.

SPENER, Philipp Jakob. Pia desideria. Frankfurt am Main: Edtior Johann David Zunners, 1676.

STRETTON, Hesba. The child's life of Christ: or the wonderful life. Philadelphia; Chicago: J. C. Winston \& Co., 1891. Com ilustrações de Heinrich Hofmann e de Berhard Plockhorst.

VOLTAIRE. Histórias das cruzadas: com ilustrações de Gustave Doré. São Paulo: Madras, 2015.

WILDE, W.A. List of the Wilde Bible pictures. Boston: W. A. Wilde Company [191?]. Disponível em: < https://archive.org/details/listofwildebible00wawi >. Acesso em: 4 set. 2019.

WILDE, W. A. Wilde's bible pictures: a selected list of sixty subjects to illustrate the International Sunday school lessons for 1916. Boston: W.A. Wilde Company, 19151916. In: Página da Library of Congress. Disponível em: < https://www.loc.gov/ item/2005692661/> .Acesso em: 4 set. 2019.

WILDE, W. A. Wilde's Bible Pictures: Beautiful and exact half-tone reproductions from photographs and steel engravings for use in the Sunday School and the Home (classic reprint). Forgotten Books, 2018.

\section{Fontes iconográficas}

Figuras 1-3 e 8-10; 12: Digitalizações do TCC

Figura 4 - 6: WILDE, W.A. List of the Wilde Bible pictures. p. 1-2 e 5-6. Disponível em: < https://archive.org/details/listofwildebible00wawi >. Acesso em: 4 set. 2019.

Figura 7: BROWN, George P. Brown's famous Pictures, catálogo, cerca de 1924. In: Hdl.huntington.org. Disponível em: < https://hdl.huntington.org/digital/collection/ p9539coll1/id/5876/ >. Acesos em: 4 set. 2019.

Figura 11: Doré, Gustavo. Roofless. In: London: a pilgrimage, 1872. In Chapter XV, 1862. In: página do Museum of London. Disponível em: < https://www.museumoflondonprints.com/ image/766692/gustave-dore-roofless-1872 >. Acesos em: 4 set. 2019.

Figura 12: BROWN, Ford Madox. Work. In: Birmingham, 1893. Disponível em: < https://en.wikipedia.org/wiki/Work_(painting) >, acesso em 28 de agosto de 2019 .

Submetido em: 2-10-2019

Aceito em: 27-11-2019 